\title{
12. COLLABORATIVE LEARNING - A POSSIBLE APPROACH OF LEARNING IN THE DISCIPLINE OF STUDY MUSICAL ANALYSIS
}

\begin{abstract}
The musician's typology is anchored, according to the traditional perception, within the limits of an individualistic image, which searches, develops and affirms its creativity following an individual training process. The collaborative learning is one of the educational patterns less used in the artistic education, being limited to several disciplines whose specificity requires appurtenance to a study group (for instance chamber training, orchestra). The method's application to the theoretical disciplines often encounters reserves both on part of the teachers and the students as well, because of the efforts required for its design and implementation. The study herein offers a possible approach of collaborative learning within the course of study Musical Analysis, pleading for the need of the social component development of the learning activities of the instrumental performer student, by his involvement within a study group.
\end{abstract}

Key words: creativity, cooperation, group study, music analysis

\section{Introduction}

The educational typology of the student pertaining to the vocational branch of instruction is particular by its double ramification - collective and individual. The individual learning is achieved both following personal study and within the instrument classes, the relationship teacher/student being, in this case, determinative in the motivation consolidation, attaining performing excellency, in building a set of instruments necessary to the approach of the musical repertory. The collective learning is achieved, at its turn, on two study directions: instrumental, by inclusion in chamber and/or orchestral groups and theoretical, with a special curriculum, intended to complete the knowledge in the instrumental field with an analytic, historic and stylistic approach of musical texts in the specific repertory.

With regard to the learning by means of a group activity, the studies performed by the researchers in the field of music psychology and educational sciences focused, until now, upon the implications, either positive or negative, of collaborative learning, achieved in the instrumental, chamber (quartet, quintet) or orchestral assemblies (e.g. Ford\&Davidson 2003, Ginsborg\&King 2012, Malhotra 1981, Murnighan\&Conlon 1991, Seddon\&Biasutti 2009, King 2004, Young\&Colman 1979). Moreover, there are studies proving the benefits of the collaborative learning in musical specializations, which involve, by definition, an activity mainly individual: composition or improvisation (e.g. Berret 2006).

The training of the musician student on theoretical-analytical streaming involve learning activities similar to the non-vocational fields, but which are apparently taken from the context of the activities' typology, specific to the

${ }^{142}$ Lecturer PhD, "George Enescu" University of Arts from Iași of Romania, email: gabriela_vlahopol@yahoo.com 
musical field. The phenomenon occurs due to the individual placement in an extended study group (between 35-50 members) and minimization of the personal contribution to the learning process by adopting a traditional-type information transmission pattern. The education system becomes closed and self-protective, a system in which the information holder and provider is the teacher exclusively. In time, the phenomenon may lead to the decrease of the student's interest and motivation, to the development of adverse and disruptive attitudes in class, to absenteeism and, finally, to the risk of failure.

As pedagogical instrument, the Collaborative learning aims to place the learning responsibility upon the student, the teacher waiving the status of absolute knowledge holder and providing an accessible, easy to uptake knowledge. This study proposes several solutions of approaching the learning activity within the discipline of study Music analysis, based on a working instrument grounded on the group activity, underlining the advantages of approaching this strategy and several implementation modalities specific to the discipline.

\section{Premises}

It is possible for a team exclusively conducted by the teacher, hierarchized in descending order from the beginning, with students who closely follow the instructions provided by the leader not to offer sufficient development opportunities of information understanding and it does no create the possibility of students' involvement in the decision-making process (Webster, 2011). Webster says that the mere argument of "learning-by-doing" is not enough for active involvement of the student in the act of learning, but his encouragement is necessary in order to associate the new information with the old ones by using collaborative-type working units and his engagement in working techniques which entail problematizations and hypotheses solving.

"Cooperative learning" is one of the main learning patterns (self-directed learning, cooperative learning and inquisitive learning), recommended by the reforms in the European educational systems, in particular the English system (Yang 2004). Collaborative learning (CL) represents a learning/teaching technique and, at the same time, a philosophy intensively discussed in the educational literature in general, as well as in various disciplinary branches, in particular, but absent for a long time from the field of music education ${ }^{143}$. Although many definitions of the method were given, there is a relative confusion regarding its meaning, collaborative learning being characterized as an "umbrella" term which includes a variety of approaches of cooperation and collaboration, or as an extended approach deriving from the student/teacher ${ }^{144}$ interaction.

The cooperative learning is defined as an educative format involving two or more interacting students, with the purpose of mutual support in assimilating an

\footnotetext{
${ }^{143}$ Luce, W. David, Collaborative learning in music education. A review of the literature, The Nineteenth International Seminar on Research in Music education: Reports of recent research in music education, August, 39, 2002, University of Gothenburg, Sweden, p. 1

144 Ibidem
} 
academic material ${ }^{145}$. The students are thus offered the opportunity to carry out course-related activities, others than watching or listening the teacher lecture (Felder, 2008, p. 7). By this process, the students mutually accept their differences, negotiate the differences of opinion and reach an agreement in elaborating an assignment. The collaboration requires on part of the students individual reflection time, of thoughts processing and their verbalization to the group peers. The main purpose of CL is the interdependency - the ability to become a knowledge consumer, a knowledge provider, by placing responsibility upon each member of the study group with regard to the assimilation and learning level of the others.

Many studies certify the benefits on multiple plans which the cooperative learning has in increasing the academic performance, irrespective of the training field (Eslamian, Aref \& Aref 2012, Rama 2003, Cooper \& Mueck 1990, Johnson, Johnson \& Scott 1978, Singhanayok \& Hooper 1998, Slavin 1983, etc.). The discipline Music analysis is intended both to complete a knowledge assembly, necessary to the student performer in order to develop its ability to understand the music he approaches, but is also a learning instrument to be used in the proper said practice of performing (delimitation of the work sections, their sound correlation based on resemblance and/or contrast, articulation of memorizing benchmarks, valid in the act of performance, perception of harmonic and tone nature aspects and their use in the part learning and memorization, as well as in case of accidental memory falls during execution, correlations at stylistic level, with works from the same repertory or historical age etc.).

The increase of efficiency in information assimilation and in the approaching modalities of a part structure determines radically the understanding of a work and implicitly the excellence degree of the performer students. Concurrently, the efficiency of the theoretical curriculum in vocational education (music history, harmony, polyphony, musical aesthetics, musical analyses, folklore) will be most of the times closely connected to the information accessibility degree and modalities of information provision, which implies challenging and ingenious methods and techniques.

Although CL pertains to the didactic strategies group named innovative or modern, the classification is rather due to its novelty in the current context of the teaching methods, anchored in the traditional model centered on the teacher, lecture-type teaching, respectively. Due to the discipline specificity, which implies to an equal extent frontal teaching modalities but also practical activities, the dynamic of Music analysis course offers CL application opportunities, but in a particular manner, in well-established group moments and configurations. The high number of students (between 30-50), the insertion of the practical application in the teaching process, the issues related to the group characteristics (fluctuating presence of students, group heterogenicity at the

\footnotetext{
${ }^{145}$ Willson, Charles E., The Effects of Cooperative Learning and Teaching Strategies on Student Achievement with Implications for Faculty In-Service Education, Doctoral Dissertation, Nova Southeastern University, March 1996, p. 24
} 
level of assimilation capabilities of specific information, diverse musical experience) are just several factors directly influencing the method applicability as well as its efficiency.

\section{Collaborative learning on Music analysis course. Advantages}

The application of the CL method in the activities of the Music analysis course may be used on two distinctive directions: in the lecture, in the demonstrative-type moments and in the practical seminars (laboratories). The purposes of the instrument use are various, particularized on the discipline specificity: (a) ensuring an active cognitive processing of information during the lecture by its alternation with applicative activities in working teams; (b) involvement of each individual in the analysis exercises on the music part; (c) opinions and feedback from each group, with regard to the information understanding level by the results achieved following analysis or the acquiring degree of the terminology specific to the discipline; (d) a high involvement degree of the individuals in heterogeneous groups from the point of view of specificity and musical training; (e) encouraging of expressing contradictory opinions and of multiple solutions with regard to the performance of a part structure; (f) development of the abilities to formulate and express the analyses results within the group and/or in front of the group, as well as of the tolerance degree in their manifestation.

Compared to the frontal method knowledge teaching/application, the application of the CL-type working modality has various benefits, Panitz\&Panitz (1997) ${ }^{146}$ offering in this regard a set of 38 advantages of method application, reaching multiple levels: cognitive, psychological, social, behavioral, etc. Particularizing the argumentation within the Music analysis course, we can offer several benefits of introducing CL within the discipline:

a. Active participation of the student to all the stages of performing a musical analysis (multiple audition, placement of graphical benchmarks on the part, interpretation of tonality, harmony, of the correlation among the sections etc.), involving the development of musical thinking skills.

b. Development of critical thinking on a musical work favors the memorization process, impacting both the consolidation of a general musical knowledge assembly and the performing activity specific to each instrument.

c. Student's acquaintance to the analytical language and the specific instruments of approaching and understanding a part determines the increase of interest for the discipline Music analysis, as well as for the set of associated collateral disciplines (stylistics, aesthetics, harmony, polyphony).

d. Interaction within the working groups, which implies verbalization of opinions and answers, argumentation of options divergent from those of the group, formulation of question develops the oral communication skills of the musicians. The benefit is all the more important as it can resolve one of the major deficiency of this category of students, specifically oriented to the

\footnotetext{
146 Panitz, T. \& Panitz, P. (1997), Encouraging the Use of Collaborative Learning in Higher Education http://home.capecod.net/ tpanitz/tedsarticles/encouragingcl.htm, 20.10.2015
} 
individual work and centering on a personal, own vision, feature they acquired following long experience in approaching and executing a musical part.

e. Development of public speaking. Most of the students are reluctant to the formulation of personal opinion in front of the group, facing fears related to general criticism, alteration of personal image, judgment error or even awkwardness of proper verbalization. Public speaking represents for the musicians a frequent deficiency, created in the context of their manifestation mainly by the act of performing and due to the importance of the teacher/student relationship since the first years of training as performers. Following CL constant use, public speaking is carried out in a healthy, safe psychological context, from which the critical attitude, either constructive or ironic is eliminated. Furthermore, a side of the artistic personality is developed, necessary to a complete musician, which transmits both emotions and coherent and competent ideas by music.

f. Testing of assessment alternative methods (Panitz\&Panitz 1997), different from the individual traditional tests. The Music analysis course proved the written tests-based assessment as relevant and efficient, during which the student personally faces the novelty of the musical part, the imperative of formulating a personal solution to the issue of a work structure. Nevertheless, the approach of new assessment modalities, based on musical analyses divided to students' pair offers the opportunity to the students who express scarcely in writing of becoming convincing in an oral, explanatory speech. At the same time, teamwork involves personal reviews of knowledge, working in a pace proper to each partner, better solution on the form of a work, construction of an optimal strategy of presenting the analysis within laboratories, mutual balancing of each individual personal contribution, in every stage of carrying out the task, aspects which involve interior and exterior calibrations of partners, which lead to the formation of important teamwork skills.

g. Midkiff \& Thomasson (1993) affirm the existence of three fundamental learning types: kinesthetic, auditory and visual ${ }^{147}$. The lecture-type format of the Music analysis course is mainly auditory and visual. The CL use may imply activities from all the three categories: when the students have to execute on their own at the piano the musical example subject to analysis, when they discuss on the analytical variants or when they present the analysis outcome in front of the class (by writing at the table, execution, explanation). All these activities may determine a diversification of the assimilation, verification and application modalities of information provided by the teacher.

h. Promotion of learning and teaching innovation represents one the modalities tailoring on the extracurricular preoccupation of the students, in which technology, computer and the unlimited information and of an amazing diversity provided by the virtual environment are the fundamental benchmarks of knowledge' accessing and handling. The change of the traditional learning

\footnotetext{
147 Midkiff, R.B., Thomasson, R.D. (1993), "A Practical Approach to Using Learning Styles in Math Instruction", Springfield, Il: Charles Thomas Pub., p. 86, accessed on Google Books in 23.11.2015
} 
instruments, modernization and opening towards new approaching types of the discipline Music analysis may determine the increase of interest for the object of study, of the involvement degree, of satisfaction and pleasure to discover new information by usual means and not only by those provided by the teacher by traditional methods.

\section{Example of CL use in the activities specific to the discipline Music analysis}

The CL specific techniques were approached in various studies with general or particularized applicability on a certain field of study, their diversity generating multiple writings regarding their efficiency, advantages and disadvantages of application, as well as an entire series of promotion and training policies in the field of CL. Panitz\&Panitz (1997) offer a complete description of the CL techniques (reading the book of Slavin (1990)) ${ }^{148}$. The present study intends to enumerate several possible modalities of CL integrating in the Music analysis course, following that in a future study to provide a detailed route of method implementation, with all its stages.

a. The Think-Pair-Share ${ }^{149}$ technique represents a big step in accommodating the students with the teamwork due to the aggressive character of information transmission. The student receives the task to analyze a musical element first personal, subsequently he compares the personal opinion to that of a team partner and, finally, after the negotiation of solutions, they are shared with the class. The exercise is extremely efficient for low number laboratory groups, the exposure time being limited for each pair. For large groups, a precise number of teams may be appointed (4 teams for 24 students), the remaining students forming control groups with different tasks.

b. Peer-review is a technique combining individual with pair working. The student receives from the teacher as an individual task the carrying out of an analysis of a musical work, on the appointed day, he gives the teacher and the team partner a copy of the assignment, following that the assessment to be carried out by both parties and critically discuss in the teacher/working pair group (sections' delimitation mistakes, terminological confusions, errors of tone, writing interpretation etc.).

c. Team assessment - it can be carried out following presentations of analyses performed by the study groups outside the course hours, as short and long-term assignments. Each group will have an established time for presentation, the other teams having the role of assessing both the accuracy of the analysis and the presentation methods (eventually according to a mutually agreed upon or

\footnotetext{
148 Co-op, Co-op (Kagan 1989); CIRC-Cooperative Integrated Reading and Comparison (Madden, Slavin, Stevens 1986); Group Investigation (Sharan \& Sharan 1976); Issues Controversy (Johnson \& Johnson 1987); Jigsaw (Aronson et al 1978); Jigsaw II (Slavin 1983): Learning Together (Johnson \& Johnson 1987); TAI-Team Assisted Individualization (Slavin, Leavey \& Madden 1986); TGT-Teams-Games (Tournament 1978); STADStudent Teams Achievement Divisions (Kagan1978): Structures (Kagan 1989). http://home.capecod.net/ tpanitz/tedsarticles/encouragingcl.htm

${ }^{149}$ Working technique whereby the solution of the problem is carried aut progressively from individual to pair and finally presented in front of the class (https://www.teachervision.com/group-work/cooperativelearning/48547.html).
} 
teacher established schedule), opinions expressed within final discussions, aiming to improve the analytical approach methods, teamwork, presentation, etc. The method can be easily applied during the Music analysis laboratories due to advantages it holds in relation to the discipline specificity: (a) it may involve a large number of students, each group containing 5-6 members; (b) the presentation of the musical analyses results may be flexible as length, depending on the formal structure, to which the application is made (in case of large structures - form of sonata, multipartite genres, sonato-symphonic genres, etc. -, in order to ensure a thoroughness and detailing of results, the presentation may require longer time); (c) the student groups may include members, with various instrumental specialties, with different school performances and musical training level, stimulating thus the involvement and the interest, as well as the knowledge assimilation degree for students with poor results or with perturbating attitudes.

d. The application of Jigsaw ${ }^{150}$ technique may become an important element to diversify the applicative activities during the hours of Music analysis, both in its theorized variant in the specialty studies and in derivative formulations. The strategy may be introduced in the teaching type lessons, by distributing the content of a lesson referring to a musical genre in a number of sections (related to the historical evolution, style etc.), distributed to one single student in the study groups, previously formed. Each of these students has a double task: to cooperate with the other "specialists" in the other groups in order to establish strategies of teaching, explanation and ensuring coherence to the final content (so that the overall image of the genre evolution appear unitary and logical) and to teach to the group peers the designated course section. At the same time, the working instrument may be applied on an extended numerical segment, in which the group of students represent the team and the working groups become individualities with distinctive tasks, thus facilitating the individual effort and focusing on the teamwork. The strategy may be used in practical activities of musical analysis as well, by segmenting the formal structure of the part subject to debate and the distribution of the component sections on individuals/working groups.

e. Round Robin (Barkley, K. Cross \&Major, 2004) is one of the most dynamic group discussion techniques, which entails concentration and obtaining short term solutions, focusing on clearly specified items, creativity in generating new ideas, centering of debate on efficiency by eliminating the down times, the strategy generating an intense, concentrated, relaxed and amusing working atmosphere. The method application in the musical analysis exercises may be achieved on round cycles grouped on formal sections, on topic processing modalities, classification of formal categories or it may be one of the modalities to review the subject on study module. Besides the said examples, the teacher

\footnotetext{
${ }^{150}$ Jigsaw is a cooperative learning technique in which students teach part of the regular curriculum to a small group of their peers (Aronson et al.,1978) in Moskowits, J.M., Malvin, J.H., Schaeffer, G.A., Schaps, E. Evaluation of Jigsaw, a Cooperative Learning Technique, Contemporary Educational Psychology 10, 104-112 (1985), p. 104
} 
may extend the series of working techniques by adjusting other methods, which, although adequate to the fields in which the theoretical side weighs the most, they can find resonance in the music instruction.

\section{Conclusions}

There is a large variety of CL type activities, but their common element is the focus on the students' involvement in exploring and applying the taught material. Each individual actively participate, cooperates as partner or member of a study group. The group dynamic is activated by the addressed challenges and questions, by the discovery of the most efficient means in their solving. Although CL is based on well grounded educative principles, its application encounters in the music instruction as well a certain resistance both on part of the students, required to come out their own comfort zone and actively participate to the education act, but on part of the teachers as well, most of the arguments being generated by the lack of knowledge of the strategy implementation modalities.

The CL adoption in the Music analysis course does not eliminate definitively the classic teaching process, based on lecture, listening and writing, the latter coexisting besides other didactic instruments based on active learning discussions and experiments. CL may determine radical transformations in the students' attitude towards the discipline, the act of learning, determining a short term increase of the school results and a long term formation of a complex artistic, multilaterally developed personality. At the same time, the CL approach may determine a change of the conception in itself of the teacher, who partially waives the statute of expert in providing knowledge, evolving to the posture of designer of new intellectual experiences, as part of an efficient and sustainable learning process.

\section{References}

1. Ahmad, Z. \& Mahmood, N. (2013). Effects of Cooperative Learning vs. Traditional Instruction on Prospective Teachers's Learning Experience and Achievement. Journal of Faculty of Educational Sciences, Ankara University, 43(1), 151-164

2. Al-Ismaiel, A.A. (2013). Collaborative blended learning with higher education students in Arabic context. [Phd Thesis], University of Wollongong, New South West, Australia

3. Anderson, L. \& Landy, J. (2006). Team Teaching: Benefits and Challenges, 16(1), The Center for Teaching and Learning, Stanford University

4. Barret, M. (2006). "Creative collaboration": an "Eminence" Study of Teaching and Learning in Music Composition. Psychology of Music, 34(2), 195218

5. Barkley, E.F., Cross, P. \& Major, C.H. (2005). Useful Concepts from Collaborative Learning Techniques: A Handbook for College Faculty, San Francisco: Jossey-Bass 
6. Brandler, B.J. \& Peynircioglu, Z.F. (2015). A Comparison of the Efficacy of Individual and Collaborative Music Learning in Ensemble Rehearsal. Journal of Research in Music Education, 63(3), 281-297

7. Brufee, K.A. (1984). Collaborative Learning and the "Conversation of Mankind". College English, 46(7), 635-652

8. Cangro, R. (2015). Student Collaboration and Standards-Based Music Learning: A Literature Review. National Association for Music Education, pp.16

9. Eslamian, D., Aref, K. \& Aref, K. (2012). The Influence of Cooperative Learning on Academic Performance. Jounal of American Science, 8(2), 200203

10. Felder, R.M. \& Brent, R. (2009). Active Learning: An Introduction, ASQ Hugher Education Brief, 2(4)

11. Felder, R.M. \& Brent, R. (2008). Active and Cooperative Learning. Penn State University

12. Felder, R.M., Brent, R., Oakley, B. \& Elhajj, I. (2004). Turning Student Groups into Effective Teams. Jounal of Student Centered Learning, 2(1), 9-34

13. Ford, L. \& Davidson, J.W. (2003). An Investigation of Members' Roles in Wind Quintets. Psychology of Music, 31(1), 53-47

14. Goodsell, A.S. \& others (1992). Collaboartive Learning: A Sourcebook for Higher Education, published by the National Center on Postseconday Teaching, Learning, and Assessment (NCTLA), The Pennsylvania State University

15. Johnson, D., Johnson, R.T. \& Stanne, M.B. (2000). Cooperative Learning Methods: A Meta-Analysis

16. Johnson, D.W. \& Johnson, R.T. (1999). Making Cooperrative Learning Work. Theory into Practice, 38(2), Bilding Community through Cooperative Learning, (pp. 67-73), Published by Lawrence Erlbaum Associates (Taylor\&Francis Group)

17. Kelly, J. (2002). Collaborative Learning: Higher Education, Interdependence, and the Authority of Knowledge by Kenneth Burfee: A Critical Study. Journal of the National Collegiate Honors Council, 91-100

18. King, E. (2004). Collaboration and the Study of Ensemble Rehearsal. In Proceedings of the $8^{\text {th }}$ International Conference on Music Perception \& Cognition, (pp. 11-16), Evanston, IL

19. Leikin, R. \& Zaslavsky, O. (1999). Cooperative Learning in Mathematics. The Mathematics Teacher, 92(3), 240-246

20. Luce, D., Collaborative Learning in Music Education: A Review of the Literature. The Nineteenth International Seminar on Research in Music Education: Reports of recent research in music education, (pp. 20-25). Sweden: University of Gothenburg

21. Morin, F. (2000). Developing Collaborative Partnerships for Student Teaching in Music. Internation Journal of Music Education, 6-15

22. Moskowits, J.M., Malvin, J.H., Schaeffer, G.A., Schaps, E. (1985). Evaluation of Jigsaw, a Cooperative Learning Technique. Contemporary Educational Psychology, 10, 104-112 
23. Panitz, T. \& Panitz, P. (1997). Encouraging the Use of Collaborative Learning in Higher Education. In J.J. Forest (ed.) Issues Facing International Education. Boston, MA: Garland pub.

24. Pike, P. (2014). An Exploration of the Effect of Cognitive and Collaborative Strategies on Keyboard Skills of Music Education Students. Internation Journal of Music Education, 23(2), 79-91

25. Stanley, A.M., Snell, A. \& Edagar, S. (2014). Collaboration as Effective Music Professional Development: Success Stories From the Field. International Journal of Music Education, 24(1), 76-88

26. Temmerman, N. (2001). Lessons to be Learned and Benefits to be Gained from a Collaborative School University Music Teaching Experience in an Australian Undergraduate Teacher Education Program. International Journal of Music Education, 38, 33-42

27. Warren, M. (2010). Collaborative Learning: Valuing Learning through Untraditional Means, [Paper submitted in partial fulfillment of the Master Teacher Program], West Point, New York: United States Military Academy

28. Webster, P., Construction of Music Learning,

http://www.peterrwebster.com/pubs/constructionism.pdf

29. Wilson, C.E. (1996). The Effects of Cooperative Learning and Teaching Strategies on Student Achievement with Implications for Faculty In-Service Education, [Phd Thesis], Nova Southeastern University

30. Yang, Y. (2008). The relationship between cooperative learning and second language acquisition, [Phd Thesis], University of Wisconsin-Platteville

34. Young, V.M. \& Colman, A.M. (1979). Some Psychological Processes in String Quartets. Psychology of Music, 7 (1), 12-18 